Int. J. Dev. Biol. 58: 369-377 (2014)

doi: $10.1387 / \mathrm{ijdb} .130353 \mathrm{ct}$

\title{
Two different vestigial like 4 genes are differentially expressed during Xenopus laevis development
}

\author{
MARÍA-GUADALUPE BARRIONUEVO', MANUEL J. AYBAR ${ }^{*, 1,2}$ and CELESTE TRÍBULO*,1,2 \\ 'Instituto Superior de Investigaciones Biológicas (INSIBIO, CONICET-UNT) and ${ }^{2}$ Instituto de Biología "Dr. Francisco D. Barbieri", \\ Facultad de Bioquímica, Química y Farmacia, Universidad Nacional de Tucumán, San Miguel de Tucumán, Tucumán, Argentina
}

\begin{abstract}
The vestigial gene ( $v g$ ) was first characterized in Drosophila and several homologues were identified in vertebrates and called vestigial like 1-4 (vg/l1-4). Vgll proteins interact with the transcription factors TEF-1 and MEF-2 through a conserved region called TONDU (TDU). Vgll4s are characterized by two tandem TDU domains which differentiate them from other members of the vestigial family. In Xenopus two genes were identified as vgll4. Our bioinformatic analysis demonstrated that these two genes are paralogues and must be named differently. We designated them as vgll4 and vgll4I. In situ hybridization analysis revealed that the expression of these two genes is rather different. At gastrula stage, both were expressed in the animal pole. However, at neurula stage, vgll4 was mainly expressed in the neural plate and neural folds, while $v g / l 4 /$ prevailed in the neural folds and epidermis. From the advanced neurula stage onward, expression of both genes was strongly enhanced in neural tissues, anterior neural plate, migrating neural crest, optic and otic vesicles. Nevertheless, there were some differences: vgll4 presented somite expression and vgll4I was localized at the skin and notochord. Our results demonstrate that Xenopus has two orthologues of the vgll4 gene, vgll4 and vgll4I with differential expression in Xenopus embryos and they may well have different roles during development.
\end{abstract}

KEY WORDS: ectoderm, Vgll4, Vgll4l, TONDU

Vestigial ( $v g$ ) genes are expressed in invertebrates and vertebrates, and have been shown to be involved in a variety of developmental processes. In Drosophila, Vestigial $(\mathrm{Vg})$ interacts with the transcription factor Scalloped (Sd) to regulate myogenesis and wing development (Kim et al., 1996, Simmonds et al., 1998). This binding specifically activates numerous target genes in the cell fate determination process (Halder et al., 1998, Simmonds et al., 1998). In vertebrates, several $v g$ homologues have been identified. They are called vestigial like 1-4 (vgll1-4) (Chen et al., 2004, Faucheux et al., 2010, Maeda et al., 2002). In zebrafish, two orthologues of mammalian vgll2 named as vgll2a and vgll2b (Johnson etal., 2011, Mann et al., 2007) were described. Recently, were also identified two $\mathrm{vg} / \mathrm{l} 4$ orthologues designated as $\mathrm{vg} / \mathrm{l}$ and vgll4I (Melvin et al., 2013).

The $v g / l$ genes encode proteins that have a conserved region called TONDU (TDU) motif (Maeda et al., 2002, Vaudin et al., 1999). Vgll proteins were shown to physically interact with Scalloped homologues such as Transcriptional Enhancer Factor-1 (TEF-1 also known as TEAD-1) (Gunther et al., 2004) and Myocyte
Enhancer Factor-2 (MEF-2) (della Gaspera et al., 2009, Maeda et al., 2002). Unlike other members of the Vgll family that have a single interaction domain TDU, Vgll4 has two tandem TDU motifs in its carboxyl-terminal domain suggesting that Vgll4 might form a bridge between TEF-1 and MEF-2 transcription factors (Chen et al., 2004, Faucheux et al., 2010).

In Xenopus a vgll4 gene was identified and its expression pattern was described only for late midneurula stage embryos. The expression was localized in the epidermis, olfactory placodes and neural crest cells (Faucheux et al., 2010). However, a detailed and comparative analysis of its early expression pattern during Xenopus embryogenesis is still lacking. We identified a new $v g / l 4$ paralogue and found it to be different from the previously described (Faucheux et al., 2010). We called this paralogue as $\mathrm{vg} / \mathrm{l} / \mathrm{l}$ based on it similarity with zebrafish $\mathrm{vgll} / \mathrm{l}$. The bioinformatic analysis of both Xenopus Vgll4s protein sequences revealed the

Abbreviations used in this paper: vg, vestigial gene; vgll, vestigial-like; vgll4l: vestigial like 4-like; TDU, tondu region; TEF, transcriptional enhancer factor.

\footnotetext{
*Address correspondence to: Celeste Tríbulo or Manuel J. Aybar. INSIBIO (CONICET-Universidad Nacional deTucumán), Chacabuco 461,T4000ILI - San Miguel de Tucumán, Tucumán, Argentina.Tel: +54-381-4107214. E-mail: celtrib@fbqf.unt.edu.ar ; mjaybar@fbqf.unt.edu.ar
} 
presence of the two TDU motifs (Chen et al., 2004, Faucheux et al., 2010), and new phylogenetic features of the Vgll family. In addition, the comparative analysis of the expression pattern of both genes in different developmental stages of Xenopus laevis embryos revealed undescribed and interesting distinct domains of expression for each gene.

\section{Results and Discussion}

\section{Identification and sequence analysis of vgll4 and vgll4I in Xenopus laevis}

Xenopus vestigial like 4 (vgll4) gene was first cloned in 2002 by Klein et al., (Accession Number: BC123267) and it was initially characterized as a gene of the vestigial family by Faucheux et al., (2010). In 2006, a microarray screening was performed by Chalmers et al., who identified a gene (NIBB clone XI460005) expressed in the internal ectoderm layer and named it also as vestigial like 4. Our interest in identifying novel players in epidermis development led us to search for genes expressed differentially in this tissue. We
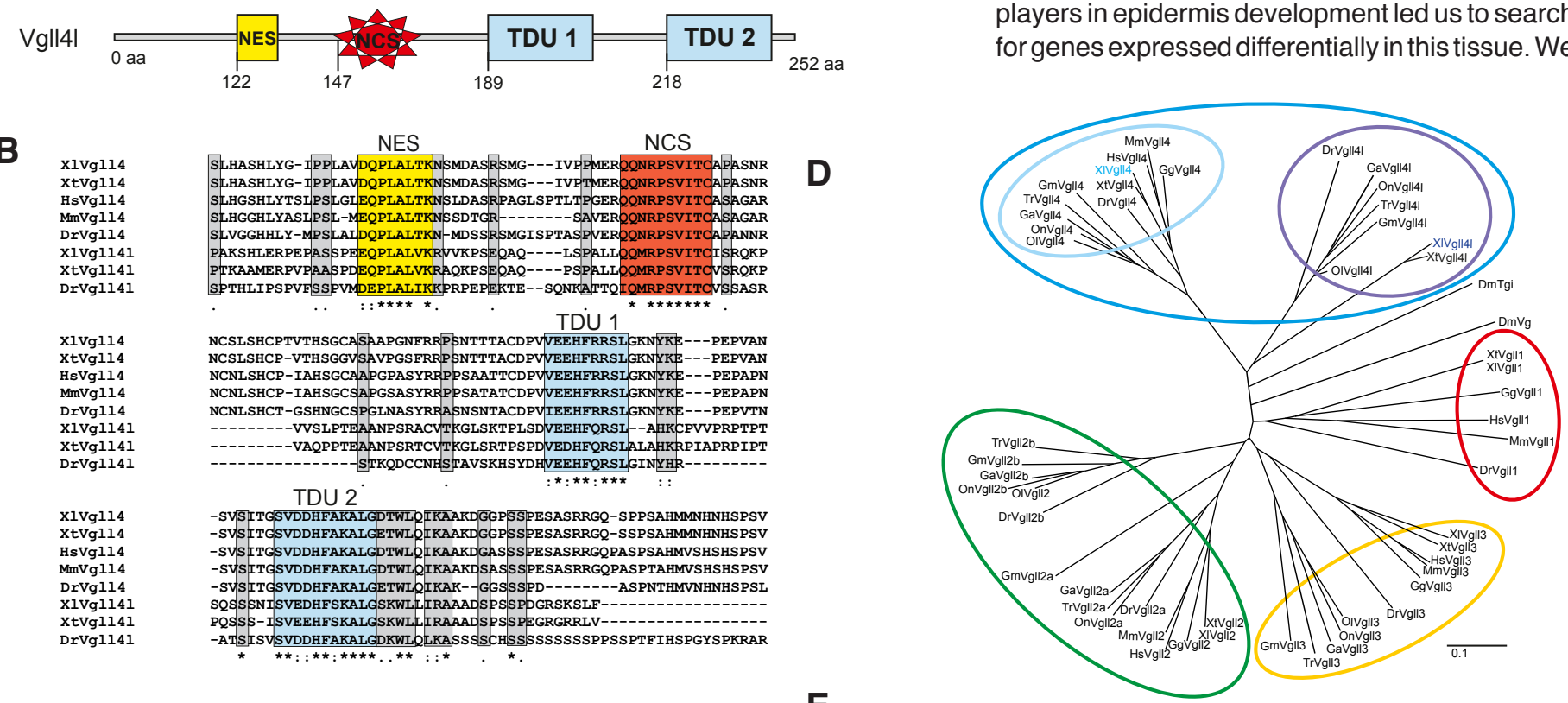

C

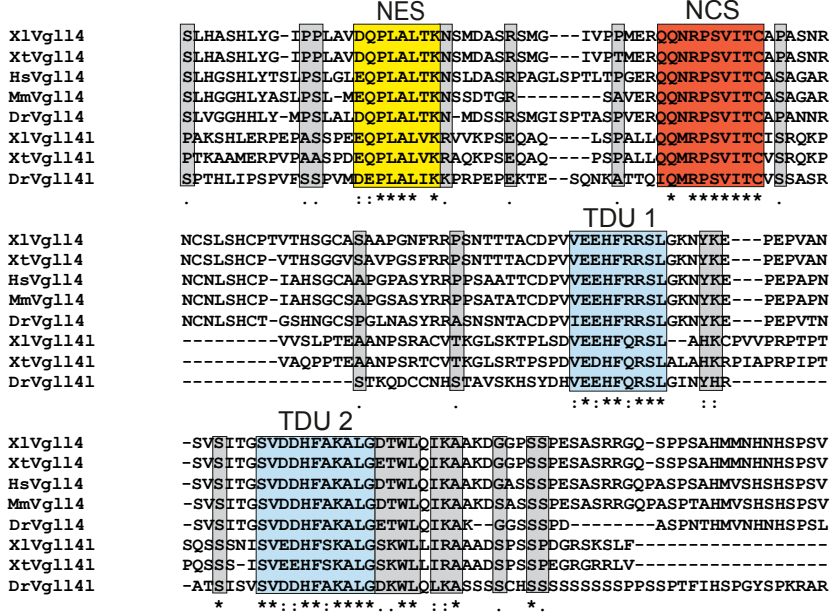

$\mathbf{E}$

\begin{tabular}{|c|c|}
\hline $1 \mathrm{lVgl14}$ & MERQQNRPSVITCAPASNRNCSLSH \\
\hline xlvgli41 & ALLQQMRPSVITCISRQKPVVSLPT \\
\hline $\mathrm{xtVgl14}$ & MERQQNRPSVITCAPASNRNCSLSH \\
\hline xtVgl141 & ALIQQMRPSVITCVSRQKPVAQPPT \\
\hline HsVgll4 & GERQQNRPSVITCASAGARNCNLSH \\
\hline DrVgl141 & TTQIQMRPSVITCVSSASRSTKQDC \\
\hline DrVgli4 & VERQQNRPSVITCAPANNRNCNLSH \\
\hline GgVg114 & VERQQNRPSVITCASANNRNCNLSH \\
\hline MmVgll4 & VERQQNRPSVITCASAGARNCNLSH \\
\hline DmTgi & ANSRPSVITOAPPKREPPEQAH \\
\hline TgVg114 & VERQQNRPSVITCASANNRNCNLSH \\
\hline BtVgll4 & VERQQNRPSVITCASASARNCNLSH \\
\hline RnVg114 & VERQQNRPSVITCASAGARNCNLSH \\
\hline MamaVgl14 & GERQQNRPSVITCASAGARNCNLSH \\
\hline PaVgli4 & QNRPSVITCASAGARNCNLSH \\
\hline Ssvgll4 & NOMRPSVITCVSSTRKPTCRS \\
\hline PtVgli4 & 2ONRPSVITCASAGARNCNLSH \\
\hline
\end{tabular}

Fig. 1. Protein sequence analysis, structural comparison, family relationships and synteny analysis of Vgll4 and Vgll4I. (A) Protein structure of Vgll4 and Vgll4I. NES, nuclear export signal; NCS, novel conserved sequence; TDU, TONDU domain. (B) Protein sequence alignment comparing Xenopus laevis (XI) Vgll4 and Vgll4I with Xenopus tropicalis (Xt), human (Hs), mouse (Mm), and zebrafish (Dr). Conserved Amino acids are shown in grey. (C) A wide comparison of the NCS region between different species. Chicken (Gg), Drosophila melanogaster (Dm), Taeniopygia guttata (Tg), Bos taurus (Bt), Rattus norvegicus (Rn), Macaca mulatta (Mama), Pongo abelii (Pa), Salmo salar (Ss), Pan troglodytes (Pt). (D) Unrooted phylogenetic tree showing the evolutionary relationship among different Vgll proteins. The tree was based on amino acid sequence alignment (see Experimental Procedures for details). (E) Analysis of conserved syntenic regions containing Vgll4 and Vgll4I loci in Xenopus tropicalis (X.t.), zebrafish (Danio rerio, D.r.), puffer fish (Takifugu rubripes, T.r.), stickleback (Gasterosteus aculeatus, G.a.), medaka (Oryzias latipes, O.I.), tilapia (Oreochromis niloticus, O.n.), cod (Gadus morhua, G. m.), human (H.s.), mouse (M.m.), and chicken (G.g.) genomes. Genes are represented as boxes and arrows indicate the orientation of the transcription unit. Boxes with the same color indicate orthologue genes. The genomic regions representations are not to scale to avoid complexity.

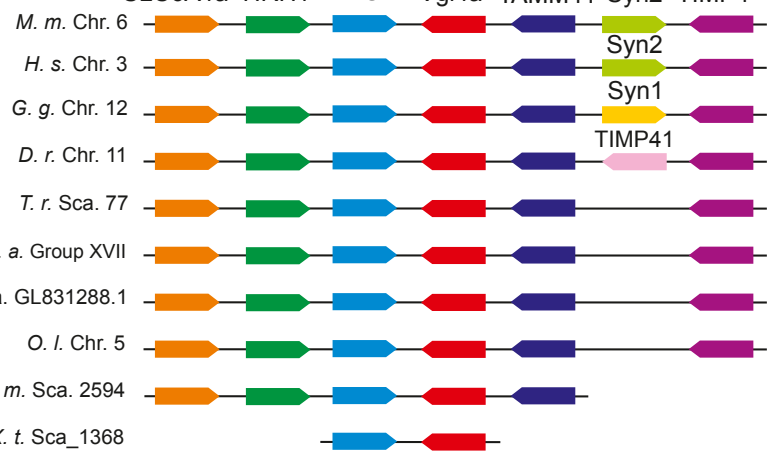

SLC20a1a Vgll4I Syn1 GAPVD1

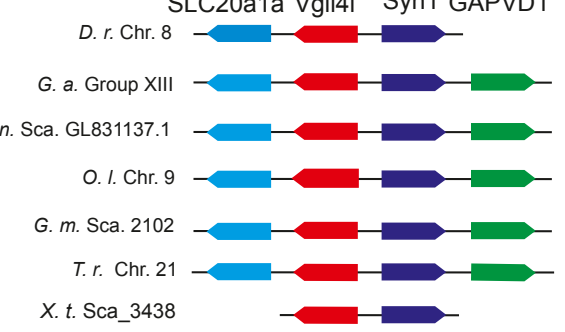

SLC6A1a HRH1 ATG7 Vgl4a TAMM41 Syn2 TIMP4 
were interested in the vestigial like 4 gene described by Chalmers et al., 2006; NIBB clone XI460005). We first sequenced and analyzed this clone in silico (Accession number: KF963131) and found it to be different from the sequence named as vestigial like 4 at the NCBI Nucleotide database (Klein et al., 2002) (Accession number: BC123267). The XI460005 clone showed high identity with a sequence called rexp52 (90\% identity) (Acc. Number: DQ096895.1), an uncharacterized gene with differential expression found in a large-scale, semiautomated whole mount in situ hybridization screening performed in Xenopus laevis(Pollet et al., 2005). Thereby, currently there are two sequences named as vestigial like 4. Notwithstanding, our bioinformatics analysis of these sequences demonstrated that they are two different genes so they should have different names. Thus, we propose in Xenopus laevis the name vestigial like 4 (vgll4) for the first cloned gene (Accession number: BC123267) and vestigial like 4-like (vgll4I) for the second (Accession number: KF963131).

In Xenopus tropicalis only a sequence corresponding to $v g / l 4$ was found into the Ensembl genomic information. We extended our in silico analysis to multiple sequences databases and this led us to find a sequence that corresponds to Xenopus tropicalis vgl/4I (Accession number: KJ690263, Fig. 1B). This gene was found in the Gurdon Institute Xenopus tropicalis EST Database (Transcript name 1012072090).

In zebrafish two sequences of 282 (Accession number: NP998440) and 266 amino acids (Accession number: NP001073467) were identified and named as vgll4 and vgll4l, respectively (Melvin et al., 2013). This finding could be extended to other bony fishes such as puffer fish, stickleback, tilapia and cod. According to their phylogenetic relationship (Fig. 1D) and sequence similarity (Fig. 1B) Xenopus vgll4 is the orthologue of fish vgll4 and Xenopus $\mathrm{vgll} / \mathrm{l}$ is the orthologue of fish $\mathrm{vgll} / \mathrm{l}$.

The protein sequence analysis showed that Xenopus laevis Vgll4 has the same sequence that the previously described Vgll4 (Klein et al., 2002, Faucheux et al., 2010). The bioinformatic analysis of Xenopus laevisand Xenopus tropicalis Vgll4I protein sequence allowed us to identify the two TDU motifs that characterize Vgll4 co-factors (Fig. $1 \mathrm{~A}, \mathrm{~B}$ ), and the putative NES (nuclear export signal) motif. When we compared Vgll4 and Vgll4I with Vgll4s from other species, we found an undescribed conserved region that we identified as NCS (novel conserved sequence) (Fig. $1 \mathrm{~A}, \mathrm{C}$ ). This region is unique in vgll4 genes and probably can act as a feature that differentiates Vgll4s from other members of the Vgll family and could interact with other protein components. A phylogenetic tree based in amino acid sequences indicate that Vgll genes of different species can be organized into four different groups, Vgll1, 2, 3 and 4 (Fig. 1D). This phylogenetic analysis is in agreement with Faucheux et al., (2010) and Koontz et al., (2013), who demonstrated that Vgll1-3 are related to Drosophila $\mathrm{Vg}$, while all Vgll4s are related to the recently identified Drosophila orthologue, Tgi. A divergence between Vgll4 and $\mathrm{Vgll} / \mathrm{l}$ is reflected in the extent of conservation of the
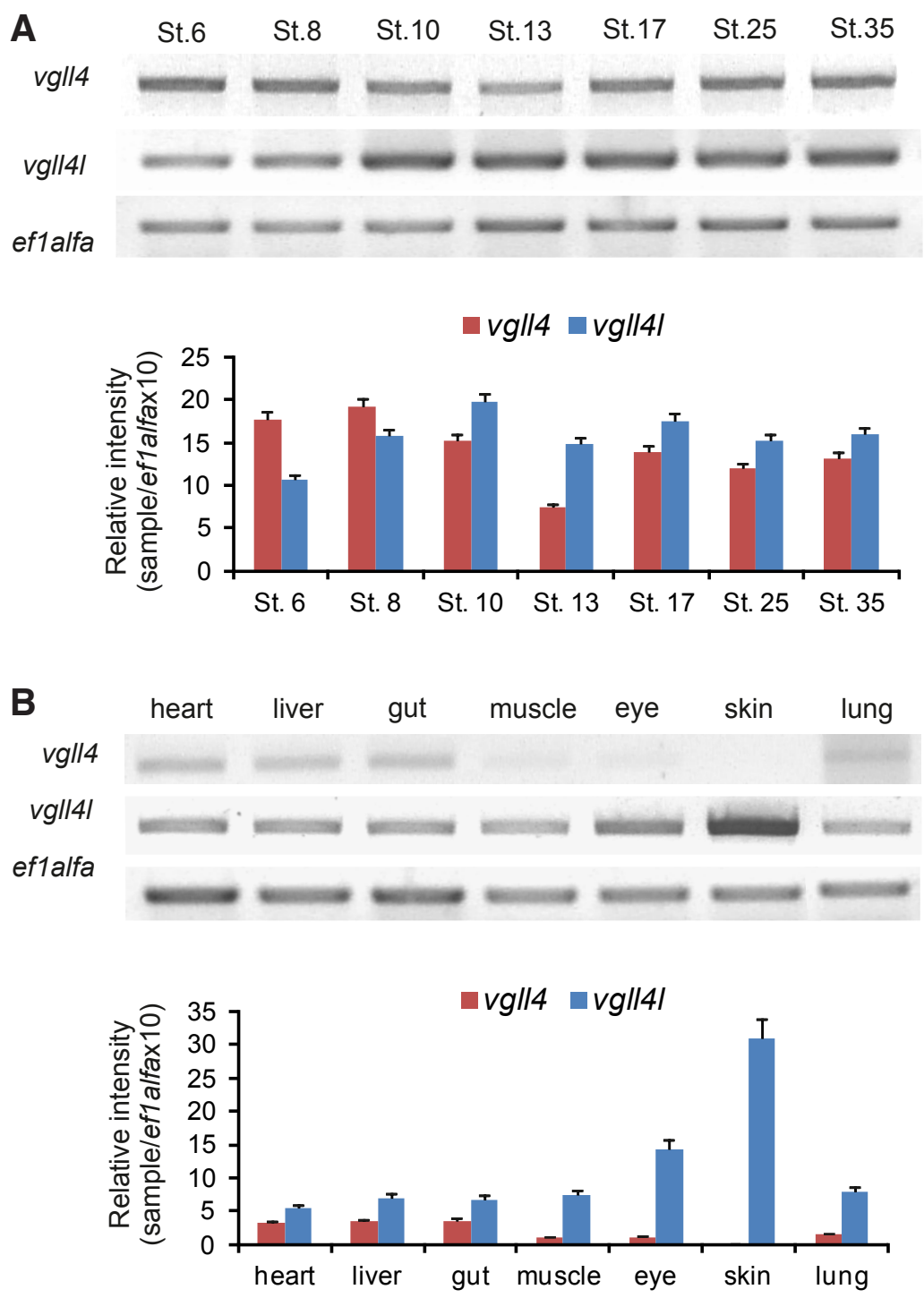

C

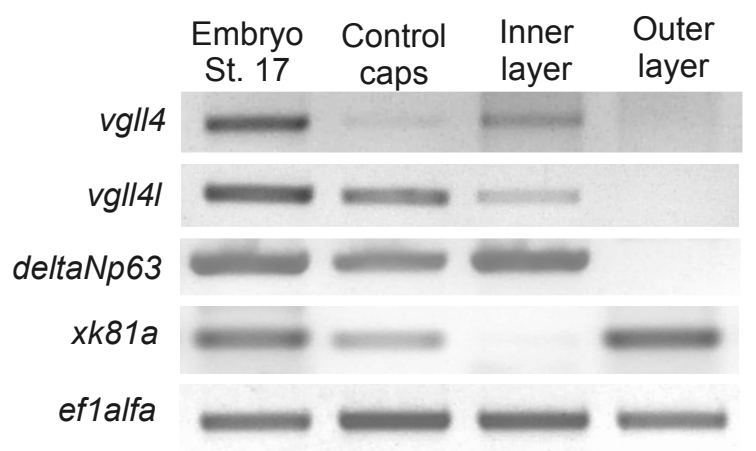

Fig. 2. RT-PCR analysis of vgll4 gene expression in embryos and adult tissues. RT-PCR was performed on total RNA extracted from embryos at different embryonic stages, adult tissues and internal and external layers of animal caps. ef1alfa was used as loading control. (A) Temporal expression of vgll4 and vgll4I throughout development. (B) Analysis of vgll4 and vgl|4l expression in adult tissues. (A,B) Quantifications of gel are shown; the results are expressed as Relative Intensity (sample/ef1alfa $X$ 10). (C) vgll4 and vgll4I expression in isolated layers of the animal cap ectoderm. 
protein sequence: Vgll4 is more similar than Vgll4I to mammalian Vgll4s (Fig. 1D) and it also shows a high similarity with Xenopus tropicalis Vgll4 (92\%). Xenopus laevis Vgll4 has 73\% identity to human and $70 \%$ to mouse Vgll4 proteins. By contrast, Xenopus laevis $\mathrm{Vgll} 4 \mathrm{l}$ is only $31 \%$ identical to mouse and $33 \%$ to human Vgll4 and Xenopus tropicalis Vgll4I is $42 \%$ identical to human Vgll4. Furthermore, Xenopus laevis Vgll4 and Vgll4I are $40 \%$ identical while Xenopus tropicalis Vgll4 and Vgll4I are $30 \%$ identical. On the
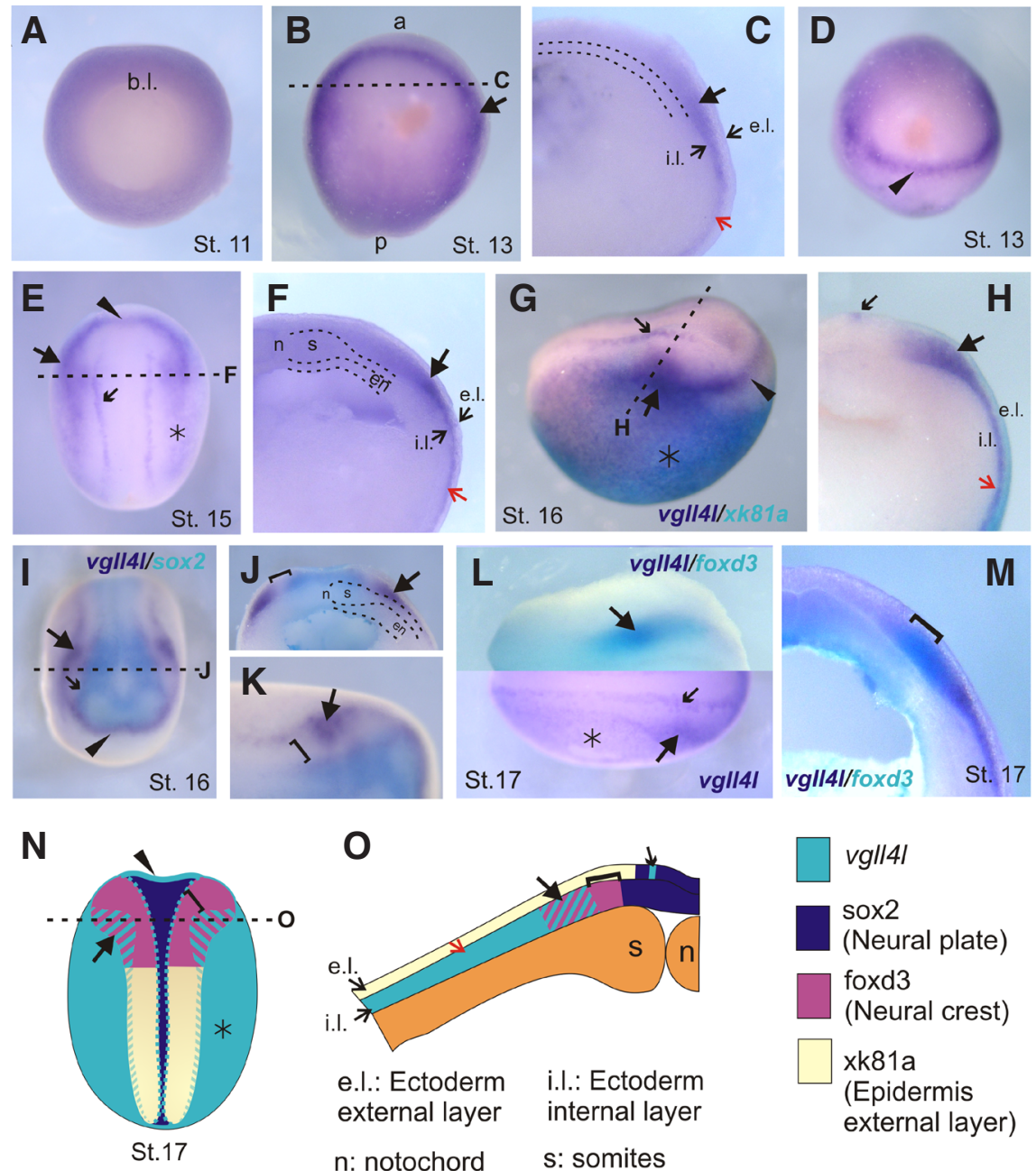

Fig. 3. Spatio-temporal expression pattern of vgll4I during early development by in situ hybridization. (A) Vegetative view. (B, E) Dorsal view, anterior to the top. (D, I) Anterior view, dorsal to the top, anterior to the front. (G) Lateral view anterior to the right. (L) Dorsal view, anterior to the right. (C, $\mathbf{F}, \mathbf{H}, \mathbf{J}, \mathbf{M})$ Transversal sections. (K) Higher magnification view of the anterior region of the embryo shown in I. Black dashed lines in $B, E, G, I$ indicate the positions of the cuts made to give transversal-sections in $C, F, H, J .(G, \mathbf{H})$ Double in situ hybridization for vgl|4I (purple) and xk81a (turquoise). (I-K) Double in situ hybridization for vgll4I (purple) and sox2 (turquoise). (L) (upper half) Double in situ hybridization for vgll4l (purple) and foxd3 (turquoise), (M) cross- sectioned embryo labeled by double in situ hybridization for vgl|4I (purple) and foxd3 (turquoise). (E, G, L) Asterisk, vgll4l expression in the prospective epidermis. (B, C, $\mathbf{E}, \mathbf{F}, \mathbf{H}-\mathbf{L})$ Large black arrow, vgll4I neural folds expression. (C, $\mathbf{F}, \mathbf{H})$ Red arrow, vgl|4l expression in the internal layer of the ectoderm. $(\mathbf{E}, \mathbf{G}, \mathbf{H}, \mathbf{I}, \mathbf{L})$ Small black arrow, vgl|4l row expression surrounding neural plate. (J, K, M, N) Brackets, vgl|4l neural folds gap of expression. (N, 0) Schematic diagrams summarizing the expression of $\mathrm{vgll} 4 \mathrm{l}$ and neural plate (sox2), neural crest (foxd3) and epidermal (xk81a) markers. (N) Dorsal view. (O) Transversal section. References: a, anterior. b.I., blastopore lip. e.l., external layer. en, endoderm. i.l., internal layer. n, notochord. p, posterior. s, somites. other hand, strong Vgll4 homology was observed in TDU domains, which are completely conserved between human, mouse, zebrafgions allows us to designate $\mathrm{Vgll4I}$ as a paralogue of Vgll4.

We analyzed the evolution of the vestigial-like genes in vertebrate genomes by synteny analysis. The genomic databases (i.e. ided us with sufficient information on the chromosome regions containing the orthologues of $X$. laevis vgll4 to perform such analysis. As shown in Fig. 1E, vgll4 and vgll4/are remarkably conserved between $X$. tropicalis, zebrafish $(D$. rerio), puffer fish ( $T$. rubripes), medaka (O. latipes), stickleback (G. aculeatus), tilapia (O. niloticus) and cod ( $G$. morhua). In the case of $X$. tropicalis $\mathrm{vgll} / \mathrm{l} /$ the genomic information available is limited but shows that this gene is syntenic with other species, since its neighbor synapsin-1 (syn-1) could be identified (Fig. 1E). Curiously, in chicken, mouse, and human genomes only the vgll4 occurred, no $\mathrm{vgll4l}$ paralogue was identified. These finding suggest that the chromosomal regions containing vgll4 and $\mathrm{vg} / \mathrm{l} / \mathrm{I}$ genes have been conserved for at least 340-390 million years, the expected divergence time for amphibian and amniota lineages (Blair and Hedges, 2005). Our results from phylogenetic and syntenic analyses support the hypothesis that in fishes and amphibians two different vgll4 genes are present.

\section{Analysis of vgll4s expression in Xenopus embryos}

First, we assessed the temporal expression profile of $v g l l 4 s$ by reverse transcriptase-polymerase reaction (RT-PCR) (Fig. 2A). Our findings agree with what has been reported for vgll4 (Faucheux et al., 2010). This gene was maternally expressed and its expression remains constant throughout development (Fig. 2A). vgll4/was also maternally expressed and the transcripts were continuously detectable until after the hatching stage (Fig. 2A). In addition, we analyzed vgll4sexpression in adult tissues. vgll4 was observed in all the tissues analyzed with exception of the skin (Fig. 2B). Previous reports showed that $v g / l 4$ was expressed at a similar level in all the tissues analyzed (Faucheux et al., 2010). The expression we found for vgll4 is different from $\mathrm{vgll} / \mathrm{l}$, which was expressed at a roughly similar level in all tissues analyzed but showed a higher expression in skin (Fig. 2B). This not tissue-restricted expression of $v g / l 4 s$ is coincident with vgll4 expression in human that was detected in the heart, kidney and brain as well as in other tissues at lower levels (Chen etal., 2004).

Then, we analyzed the spatiotemporal expression of $v g / l 4$ and $v g / l 4 l$. Previous results showed that vgll4I (named as vgll4) expression analyzed by in situ hybridization begins at gastrula stage and in stage 14 is located in the inner layer of 
the epidermis (Chalmers et al., 2006). We performed a detailed analysis of $\mathrm{vgll} / \mathrm{l}$ expression at different stages comparing it with different neural and epidermal marker genes. Our results showed that in early gastrula $\mathrm{vg} / \mathrm{l} / \mathrm{l}$ was widely expressed in the animal hemisphere (Fig. 3A). vgll4/expression was decreased in the dorsal and posterior ectoderm during gastrulation. In neurula, stage 13 onwards, it was expressed surrounding the neural plate anteriorly and laterally (Fig. 3B, black arrow; Fig. 3D, black arrowhead). Transversal sections revealed that $v g / l 4 /$ expression is restricted to the internal layer of the ectoderm (Fig. 3C, red arrow). At neurula stage the expression is restricted to the anterior and lateral neural folds (Fig. 3E, arrowhead and black arrow) and displays an expression pattern that in the ectodermal domain overlaps with the epidermal marker $x k 81 a$ (Fig. 3G, asterisk). Transversal sections confirmed that $\mathrm{vg} / \mathrm{l} / \mathrm{l}$ expression is located in the inner layer of the ectoderm compared with $x k 81 a$, which is expressed in the external layer (Fig. $3 \mathrm{H}, \mathrm{O})$. Besides, we performed a RT-PCR determination of $\mathrm{vg} / \mathrm{l} / \mathrm{lin}$ explants samples dissected from the internal and external layers of the epidermis. This analysis showed a clear $\mathrm{vg} / \mathrm{l} / \mathrm{l}$ expression in the internal but not in the external layer (Fig. 2C) that correlates with the internal layer marker deltaNp63 expression (Tribulo et al., 2012). Double in situ hybridization showed that vgll4l anterior expression corresponds to the anterior neural fold because it is complementary and does not overlap with the neural plate territory expressing sox 2 marker (Fig. 3 I,N, arrowhead). The expression of $v g l / 4 I$ in the lateral neural folds shows a gap between its expression and sox2 (Fig. $3 \mathrm{~J}, \mathrm{~K}, \mathrm{~N}$, brackets) and partially overlaps with the neural crest marker foxd3 (Fig. 3 L,M,N,O, black arrow and brackets), demonstrating that $v g / / 4 /$ expression is located in the most ventral region of the prospective neural crest. Moreover, vgll4/expression extends laterally beyond foxd3expression into the contiguous territory that corresponds to the pre-placodal ectoderm (Fig 3 E, G, I, black arrowhead and black arrow). Two rows of vgll4I expression that extend surrounding the limit between neural plate and neural crest can also be seen (Fig. 3 E, G, H, L,N,O, small black arrow). Transversal sectioning demonstrated that this expression is the only one located in the external layer of the ectoderm (Fig. $3 \mathrm{H}, \mathrm{O}$, small black arrow).

Our comparison between $v g / l 4 /$ and $v g / l 4$ revealed significant differences between their expressions. At gastrula stage both genes are expressed in the animal pole but $v g / l 4$ is more strongly expressed in the dorsal region of the embryo (Fig. 4A). At early neurula $v g / l 4$ is expressed in the anterior and posterior region of the neural plate but not in the middle region (Fig. 4 B,C, black arrowhead). The comparison between vgll4 and sox2 demonstrate that at stage 13 there is not $\mathrm{vgll} 4 \mathrm{in}$ the middle region of the neural plate (Fig. 4D). Since stage $16 \mathrm{vg} / \mathrm{l} 4$ expression is located in the neural plate (small black arrowhead) and in the neural folds (arrow) (Fig. 4 E,G,J). It also presents a weak expression in the epidermis (Fig. $4 \mathrm{~F}, \mathrm{H}, \mathrm{J}$, asterisk). Transversal sections confirmed that vgll4 is expressed in the neural plate, neural folds and epidermis of midneurula embryos (stage 17, Fig. $4 \mathrm{H}, \mathrm{I}, \mathrm{K}$ ) and also showed a

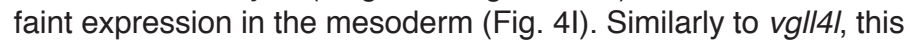
gene presents expression in the internal layer of the ectoderm (Fig. $2 \mathrm{C}, 4 \mathrm{I})$. The onset of vgll4 expression was detected earlier than in Faucheux et al., (2010) that have shown its expression since stage 16 onward. Our results extend the initial findings that reported expression of vgll4 in epidermis and neural crest (Facheux et al., 2010) but not in the neural plate.
At advanced neurula (Stage 19), vgll4/continued to be expressed at the neural crest and epidermis (Fig. 5A). At tailbud stage, vg//4I expression was located at the migrating cephalic neural crest (Fig. 5B), principally in the mandibular stream (Fig. 5 B,D; arrowhead) and continued to be located in the internal layer of the epidermis (Fig. 5 A-C; asterisk and black arrow). When the development progresses, the main expression of $\mathrm{vgll} / \mathrm{l} /$ is located in tailbud skin
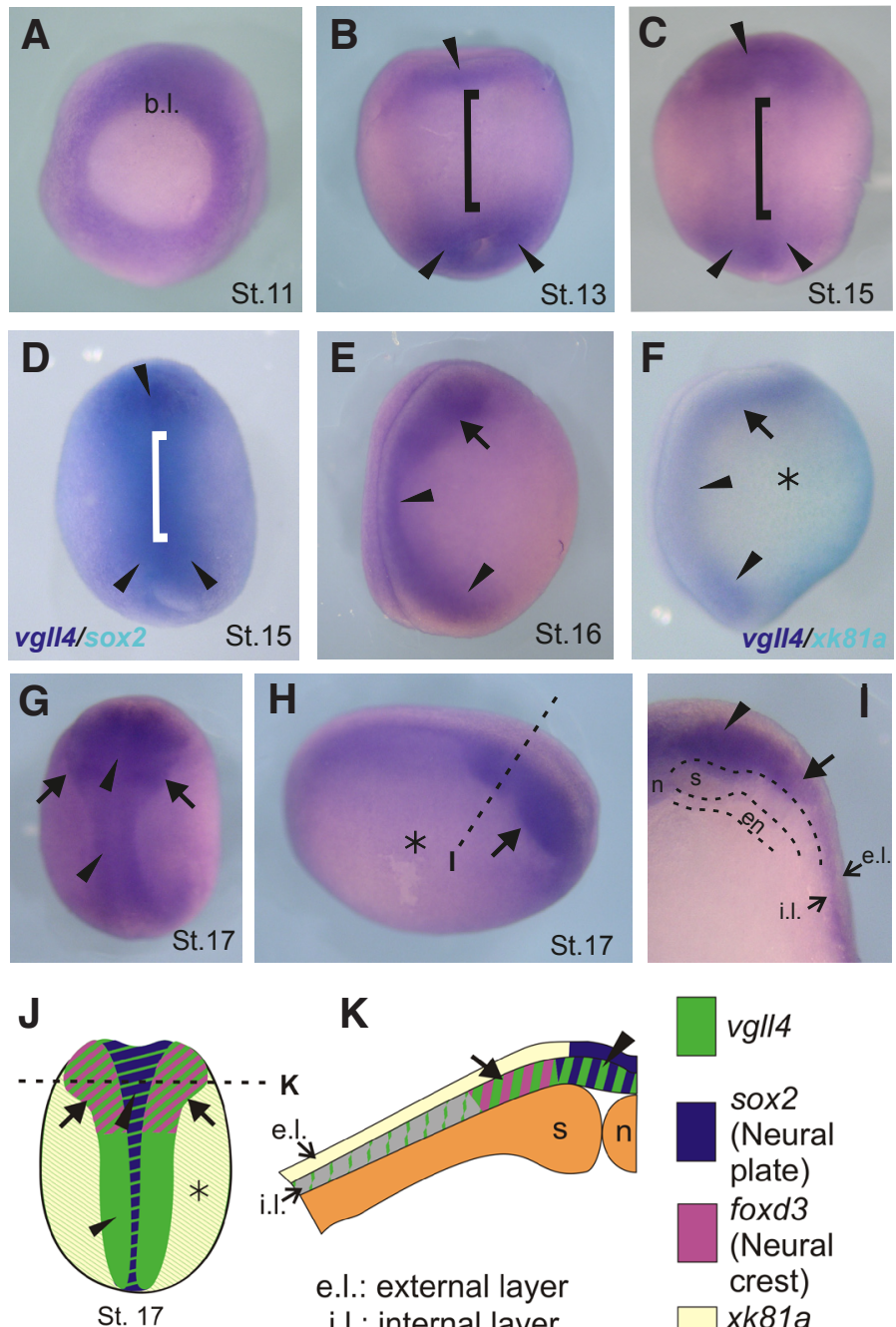

K
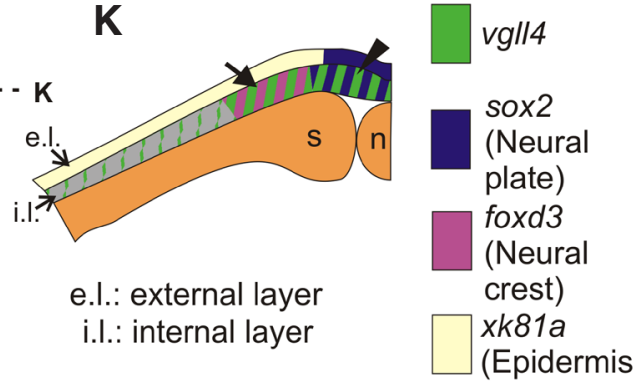

e.I.)

Fig. 4. Spatio-temporal expression pattern of $v g / 14$ during early development by in situ hybridization. (A) Vegetative view. (B-D, G) Dorsal view, anterior to the top. (E, F) Lateral view, dorsal to the left, anterior to the top. (H) Lateral view, dorsal to the top, anterior to the right. (I) Transversal section. Black dashed line in $\mathrm{H}$ indicates the position of the cut made to give cross-section in I. (D) Double in situ hybridization for vgll4 (purple) and sox2 (turquoise). (F) Double in situ hybridization forvgll4 (purple) and xk81a (turquoise). (B-D) Arrowheads, anterior and posterior vgll4 expression in the neural plate. Brackets, lack of expression in the middle neural plate. (F, H) Asterisk, weak vgll4 expression in the prospective epidermis. Arrow, neural folds vgll4 expression. Arrowhead, neural plate expression. (J, K) Schematic diagrams summarizing the expression of $\mathrm{vgll} 4 \mathrm{l}$ and neural plate (sox2), neural crest (foxd3) and epidermal (xk81a) markers. (J) Dorsal view. (K) Transversal section. References: b.l., blastopore lip. e.l., external layer. en, endoderm. i. l.: internal layer. n, notochord. s, somites. 
(Fig. 5 D,G; black arrow) and branchial arches (Fig. 5 E,G,l; black arrowheads). It is also expressed in the notochord (red arrow) and otic vesicle (Fig. $5 \mathrm{E}, \mathrm{G}, \mathrm{H}$ ). The expression of $v g / / 4$ in these stages was consistent with previous reports (Faucheux et al., 2010). At stage 19 it can be observed at the neural plate, preferentially in the anterior region and in the neural crest that is starting to migrate (Fig. 5J). At stage $24 \mathrm{vg} / \mathrm{l} 4$ is observed at migrating neural crest (red arrowheads), prospective brain (black small arrow) and somites (white arrowhead) (Fig. $5 \mathrm{~K}, \mathrm{~L}$ ). At later stages, the expression is located in the eye primordium and branchial arches and persists at
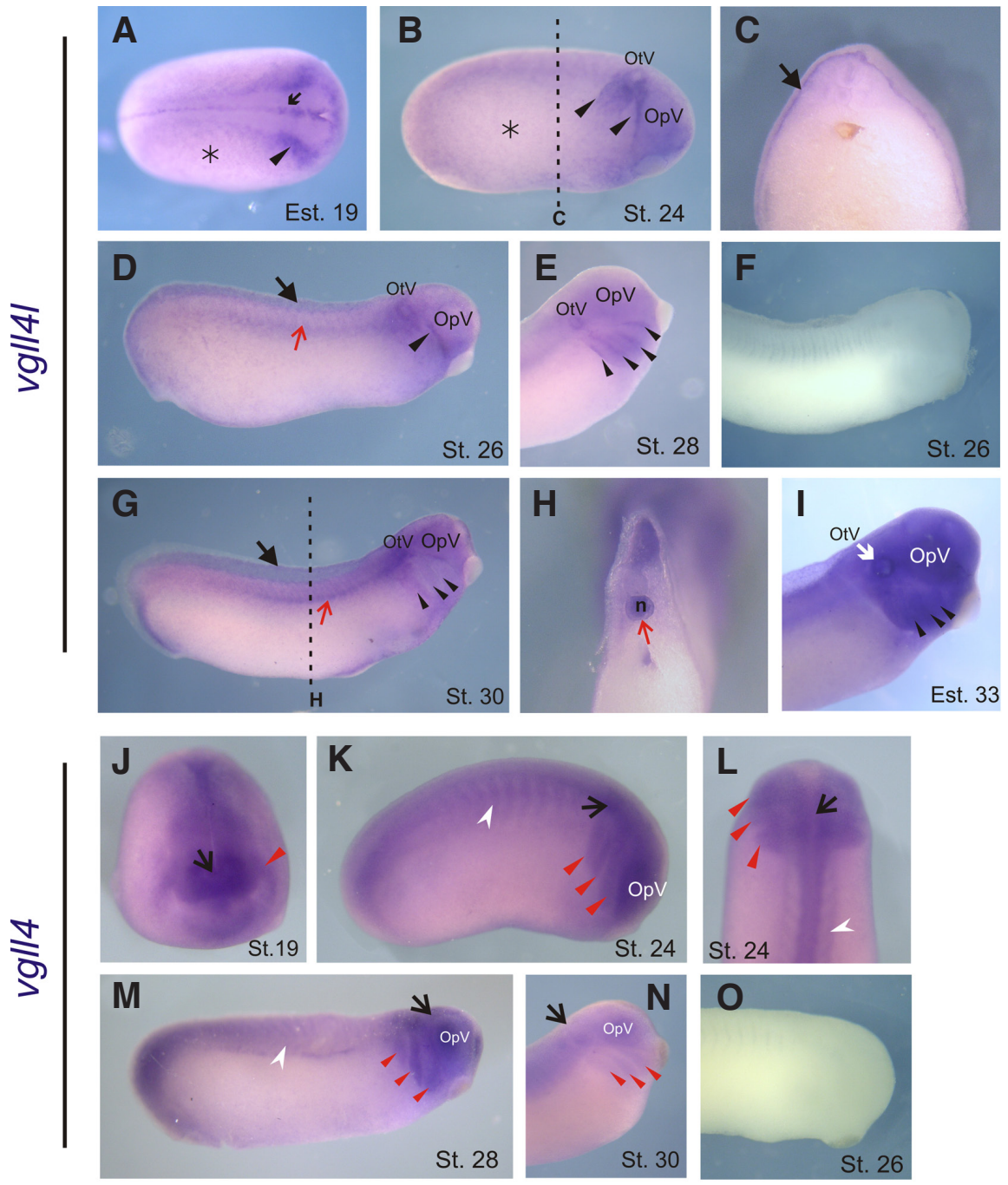

Fig. 5. Expression of $v g / l 4 I$ and $v g / l 4$ at advanced neurula and tailbud stages. (A-I) vgl|4I expression. (J-O) vgll4 expression. (A) Dorsal view, anterior to the right. (B, D, F, G, K, M, O) lateral view, anterior to the right. (C, H) Transversal section. Black dashed lines in B and $G$ indicate the positions of the cuts made to give cross-section in $\mathrm{C}$ and $\mathrm{H}$. (E, I, N) Higher-magnification views of head region. (J) Anterior view, dorsal to the top. (L) Dorsal view, anterior to the top. (F) Negative control, vgll4l sense probe. (A-B) Asterisk, vgl|4l epidermal expression. (A) Arrowhead: vgl|4I neural folds expression. (B, D) Arrowhead, vgl|4l expression in the migrating neural crest. E, G, I: Arrowhead, vgl|4l branchial arches expression. (C) Black arrow, vgl|4| expression in the internal layer of the ectoderm. (D, G) Black arrow, vgl|4I skin expression. (D, G, H) Red arrow, vgll4I notochord expression. (0) Negative control, vgll4 sense probe. (J-N) Arrow, vgll4 expression in the prospective brain. (J-L) Red arrowhead, vgll4 expression in the migrating neural crest. (M-N) Red arrowheads, vgll4 branchial arches expression. (K, L, M) White arrowhead, vgll4 somites expression. n, notochord. OpV, optic vesicle. OtV, otic vesicle. somites and brain (Fig. 5 M,N). Although vgll4and vgll4/expression at these stages have some coincidences they are not expressed expression in later in the derived skin while vgll4 do not present branchial arches and central nervous system. To the best of our vgll4/ gene expression in Xenopus.

In zebrafish $\mathrm{vgll} / \mathrm{l}$ is expressed in the epidermis since early development. During somitogenesis the expression is located in the epidermis and in the neural plate border. At later stages (24-48 hpf) $\mathrm{vg} / \mathrm{l} / \mathrm{l}$ remains located at the epidermis and also is expressed in the nose, otic vesicle, pharyngeal pouches and lateral line (Thisse et al., 2001). vgll4 in chicken is expressed in the caudal notochord and in the migratory neural crest cells (Rabadan et al., 2013). In mammals vgll4 expression was assessed only in adult tissues and its expression was high in the heart, kidney and brain (Chen et al., 2004). However, there are not reports about vgll4 expression in early mammalian development.

\section{Regulation of vgll4s expression}

It was determined in Xenopus that early ectodermal cell pattern is regulated by a BMP4 signaling pathway. BMP4 is essential for epidermal specification while low or absent BMP4 activity results in neural specification (Wilson and Hemmati-Brivanlou, 1995). Due to the complex vgll4 and $v g / / 4 /$ expression pattern in the ectoderm we analyzed whether BMP4 was necessary for $\mathrm{vgll} 4 \mathrm{~s}$ expression. To assess that, we decreased the levels of BMP4 expressing a dominant-negative truncated BMP4 (CM-BMP4) or chordin (chd) (Montero-Balaguer et al.), both antagonist of BMP4 signaling. RT-PCR analysis of explanted animal caps injected with CM-BMP4 or chdmRNA revealed an up-regulation of sox 2 consistent with the neuralization effect and a decrease in the epidermal marker $x k 81 a$. In this context we observed an increase in $\mathrm{vgll} / 4$ expression and a decrease in vgll4I (Fig. 6A). Previous results demonstrated that vgll4 expression was stimulated in a dose dependent manner by activin, but not by FGF or BMP4 signals (Faucheux et al., 2010).

We also analyzed the effect of deltaNp63, a gene that is regulated in a BMP4-dependent manner and that is required during the development of early epidermis (Tribulo etal., 2012). We carried out a loss of function in vitro experiment by microinjection of an antisense morpholino oligonucleotide MOdeltaNp63. RT-PCR performed on animal caps showed that the inhibition of deltaNp63 increased the level of $v g / l 4$ and down regulated significantly the expression of $v g / l 4 l$ (Fig. 6B). These results together with the expression analysis of $v g / l 4$ and $v g / 14$ l suggest that these genes participate in the development of different ectoderm derived tissues. 
vgll4 could be participating during neural development and vgl/4I during epidermis and neural crest development.

Recent studies demonstrated that $v g / l 4 /$ is involved in the craniofacial development of zebrafish embryos. Morpholino knockdown of $v g / l 4 /$ produced a loss of neural crest derived cartilages suggesting an important role of this gene during zebrafish neural crest specification and survival (Melvin et al., 2013). According to $\mathrm{vg} / \mathrm{l} / \mathrm{l}$ expression pattern and preliminary functional analysis in Xenopusthere is a strong possibility that this gene also participates in neural crest development. However, further studies are needed to fully understand the role of this gene.

A
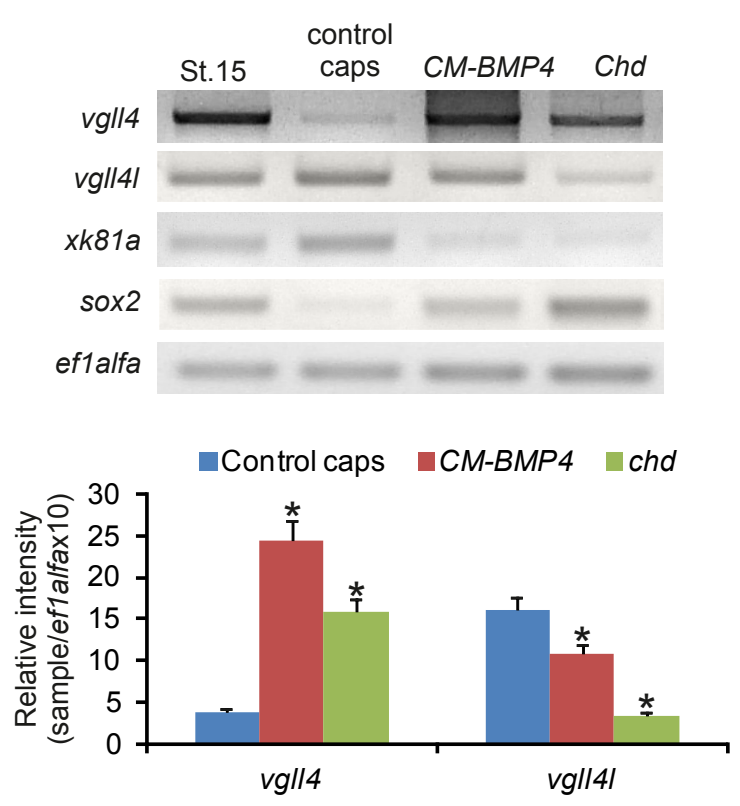

B
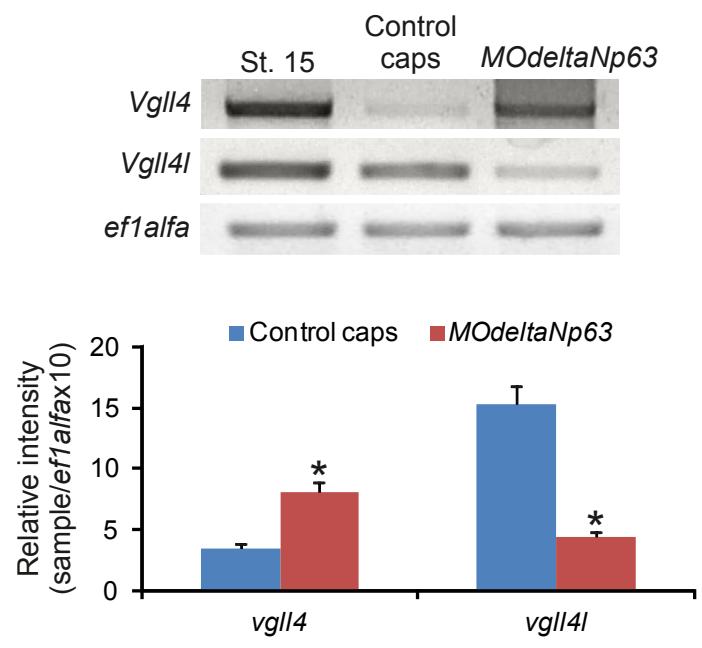

Fig. 6. Regulation of vgll4 and vgll4l expression in the ectoderm. One-cell stage embryos were injected with CM-BMP4 or chd mRNA (A) or MOdeltaNp63 (B). Stage 15- control embryos were not injected. At stage 9, animal caps were dissected. Total RNA was isolated from stage 15 embryos and treated and control caps and the expression of vgll4 and vgl|4I was analyzed by RT-PCR. ef1alfa was used as loading control. Quantification of gels is shown; the results are expressed as Relative Intensity (sample/ef1alfaX10). Differences were considered statistically significant at $\left.P<0.0011^{*}\right)$.
It was demonstrated in mammals that $v$ gll4 participates in cardiac myocytes differentiation (Chen et al., 2004). Besides, biochemical studies demonstrated that $v g / l 4$ is able to bind to inhibitor of apoptosis proteins (IAPs) playing a role in the apoptotic pathway as an apoptotic promoter (Jin et al., 2011). Nevertheless, in human embryonic stem cells (hESCs) vgll4 was identified as a positive regulator of survival. It was shown that the overexpression of vgll4 in hESCs decreases death and enhances colony formation (Tajonar et al., 2013).

Recently, an orthologue of the mammalian Vgll4 that was called Tgi/SdBP and has the two TDU domains was identified in Drosophila. In this model Tgi/SdBP suppresses tissue growth participating in the Hippo pathway by interfering with targets transcription (Guo et al., 2013, Koontz et al., 2013).

Considering the complex functions observed for $\mathrm{vgll} 4 \mathrm{~s}$ genes in other model organisms, it could be relevant to explore the differential functions that Xenopus vg/l4 and vg/l4/could have during development and organogenesis.

\section{Materials and Methods}

\section{Phylogenetic analysis}

Sequences were extracted from $\mathrm{NCBI}$ and aligned with the Clustal W program. Phylogenetic analyses were performed with the following sequences: Xenopus laevis: XIVgll1 NP_001182314, XIVgll2 NP_001080827, XIVgll3 BP689609, XIVgll4 AAI23268 (BC123267), XIVgll4I (KF963131); Xenopus tropicalis: XtVgll1 XP_002932640, XtVgll2 NP_989178, XtVgll3 NP_001072251, XtVgll4 NP_001072615, XtVg|l4| KJ690263; Homo sapiens: HsVgll1 AAH03362; HsVgll2 NP_872586, HsVgll3 EAW68870, HsVgll4 NP_001121691; Mus musculus: MmVgll1 EDL42164.1, MmVgll2 EDL05072.1, MmVgll3 NP_082848.1, MmVgll4 EDK99520; Danio rerio: DrVgll1 XM_681743, DrVgll2a NM_001025486, DrVgll2b NP_001028267, DrVgll3 XP_002663398, DrVgll4 NP_998440, DrVgll4INP_001073467; Gallus gallus: GgVgll1 XP_001234166.1, GgVgll2 ACN54257, GgVgll3 XP_416671, GgVgll4NP_001025764; Oryzias latipes: OIVgll2 ENSORLP00000015665, OIVgll3 ENSORLG00000015881, OIVgll4 ENSORLT00000005638, OIVgl|4I ENSORLT00000016519; Oreochronis niloticus: OnVgll2a ENSONIG00000015743, OnVgll2b ENSONIP00000004388, OnVgll3 ENSONIG00000004268, OnVgll4 ENSONIP00000018031, OnVgll4I ENSONIP00000013686; Takifugu rubripes: TrVgll2a ENSTRUG00000008567, TrVgll2b ENSTRUP00000030470, Trvgll3 ENSTRUG00000004178, TrVgll4 ENSTRUP00000006707, TrVgll4I ENSTRUP00000019716; Gasterosteus aculeatus: GaVgll2a ENSGACP00000007733, GaVgll2b ENSGACG00000009615, GaVgll3 ENSGACG00000006678, GaVgll4ENSGACT00000009758, GaVgll4IENSGACT00000015849; Gadus morhua: GmVgll2a ENSGMOP00000012209, GmVgll2b ENSGMOP00000020185, GmVgll3 ENSGMOP00000000452, GmVgll4 ENSGMOT00000011483, GmVgll4I ENSGMOT00000006944; Drosophila melanogaster: DmVg AAF58444, DmTgi CG10741 (SdPB NP_648658); Taeniopygia guttata: TgVgll4 XP_002187401; Bos taurus: BtVgll4 DAA16844; Rattus norvegicus: RnVgll4 EDM02166; Macaca mulatta: MamaVgll4 NP_001181777; Pongo abelii: PaVgll4 NP_001125047, Salmo salar: SsVgll4 NP_001134829; Pan troglodytes: PtVgll4 JAA19895.

The phylogenetic tree was drawn using the Phylodendron application (http://iubio.bio.indiana.edu/treeapp/treeprint-form.html). Syntenic analysis was performed using Blast tools in Ensembl genome databases. X. laevis $\mathrm{vgll4}$ and $\mathrm{vg} / \mathrm{l} / \mathrm{l}$ were used as queries.

\section{Embryo collection}

Xenopus laevis embryos were obtained by stimulating adult male and female specimens with $400 \mathrm{IU}$ and $800 \mathrm{IU}$ of chorionic gonadotropin (HCG, Elea Lab., Argentina), respectively. Fertilized eggs were obtained after natural single-pair mating and were staged according to the Nieuwkoop 
and Faber developmental table (1967).

\section{RNA isolation and RT-PCR expression analysis}

Total RNA was isolated from whole embryos, adult tissues and animal caps using Trizol reagent (Invitrogen) according to manufacturer's instructions. CDNAs were synthesized by M-MLV reverse transcriptase (Promega, USA) with oligo $\mathrm{dT}_{15}$ priming from $3 \mu \mathrm{g}$ total RNA extracted from embryos at different stages. PCRs were performed with Taq Pegasus (PB-L, Argentina) and ef1alfa was used as a loading control. The primers used were:

vgll4 5' -CAACAACATCGCTATTCTCTGC-3' and

5'-TTTTCGGAGGTCTCTTTAGGAG-3'

vgll4/ 5'-TAGAGCAATAGTATGGCCGTCT-3' and

5'-AGGAAGAGAGACCACTGGCTTT-3';

deltaNp63, 5'-ATGTTGTATCTGGAAAACAATGCTCAG-3' and

5'- GACAACGCTTCACAACCTCTG-3';

xk81a, 5'-CACCAGAACACAGAGTAC-3' and

5'-CAACCTTCCATCAACCA-3';

sox2, 5-GAGGATGGACACTTATGCCCAC-3' and

5'-GGACATGCTGTAGGTAGGCGA-3'

ef1alfa 5'-CAGATTGGTGCTGGATATGC-3' and

5'-CTGCCTTGATGACTCCTAG-3'.

PCR amplification, DNA contamination controls, and quantification of gels were performed as previously described (Tribulo et al., 2012). RTPCR was performed twice with a pool of 20 embryos each one. Quantitation of PCR bands was performed using Image s software (NIH, USA) on 8-bit greyscale JPG files. Measures were made six different times and an average was taken to performer the graphics. Values were normalized to the ef1alfa levels from the same sample and expressed for comparison as relative intensities (sample/ef1alfaX10).

\section{In situ hybridization}

vgll4 cDNA was obtained from Open Biosistems, clone MXL173699822090, BC123267=Vestigial like 4 and vgll4/ was obtained from NIBB, clone XI460005. Antisense probes containing digoxigenin-11-UTP or fluorescein-12-UTP were prepared, hybridized and stained for vgll4 (Faucheaux et al., 2010), vgll4l (Chalmers et al., 2006), sox2, xk81a, foxd3 by in vitro transcription. Specimens were prepared, hybridized and stained as described (Tribulo et al., 2012). For transversal sections embryos were cut using eyebrow knives or a scalpel.

\section{Microinjection and animal cap assay}

Xenopus laevis deltaNp63 morpholino antisense oligonucleotide (deltaNp63MO) was synthesized as described (Tribulo et al., 2012). CM-BMP4 and Chordin (chd) were donated by Dr. K. W. Cho (Hawley et al., 1995) and cDNAs were linearized and transcribed as indicated in Tribulo et al., 2004. Embryos were microinjected with deltaNp63MO, CM-BMP4 or chd mRNA and animal caps were dissected out from them using eyebrow knives as described (Aguero et al., 2012, Tribulo et al., 2004).

\section{Acknowledgements}

We wish to thank Dr. Naoto Ueno for the donation of vgll4I clone. We specially thank to Ms. Virginia Mendez for proofreading. This investigation was supported by grants from ANPCyT-Foncyt to M.J.A. (PICT20121224, PICT2013-1686) and to C.T. (PICT2013-0219), and by grants from CIUNT to M.J.A. (PIUNT 26/D506).

\section{References}

AGUERO, T.H., FERNANDEZ, J.P., LOPEZ, G.A., TRIBULO, C. and AYBAR, M.J. (2012). Indian hedgehog signaling is required for proper formation, maintenance and migration of Xenopus neural crest. Dev. Biol. 364: 99-113.

BLAIR, J.E., HEDGES, S.B. (2005). Molecular phylogeny and divergence times of Deuterostome animals. Molec. Biol. Evol. 22: 2275-2282.

CHALMERS, A.D., LACHANI, K., SHIN, Y., SHERWOOD, V., CHO, K.W. and PAPALOPULU, N. (2006). Grainyhead-like 3, a transcription factor identified in a microarray screen, promotes the specification of the superficial layer of the embryonic epidermis. Mech. Dev. 123: 702-718.

CHEN, H.H., MULLETT, S.J. and STEWART, A.F. (2004). Vgl-4, a novel member of the vestigial-like family of transcription cofactors, regulates alpha1-adrenergic activation of gene expression in cardiac myocytes. J. Biol. Chem. 279: 30800-308006.

DELLA GASPERA, B., ARMAND, A.S., SEQUEIRA, I., LECOLLE, S., GALLIEN, C.L., CHARBONNIER, F. and CHANOINE, C. (2009). The Xenopus MEF2 gene family: evidence of a role for XMEF2C in larval tendon development. Dev. Biol. 328: 392-402.

FAUCHEUX, C., NAYE, F., TREGUER, K., FEDOU, S., THIEBAUD, P. and THEZE, N. (2010). Vestigial like gene family expression in Xenopus: common and divergent features with other vertebrates. Int. J. Dev. Biol. 54: 1375-1382.

GUNTHER, S., MIELCAREK, M., KRUGER, M. and BRAUN, T. (2004). VITO-1 is an essential cofactor of TEF1-dependent muscle-specific gene regulation. Nucleic Acid. Res. 32: 791-802.

GUO, T., LU, Y., LI, P., YIN, M.X., LV, D., ZHANG, W., WANG, H., ZHOU, Z., JI, H., ZHAO, Y. et al., (2013). A novel partner of Scalloped regulates Hippo signaling via antagonizing Scalloped-Yorkie activity. Cell Res. 23: 1201-1214.

HALDER, G., POLACZYK, P., KRAUS, M.E., HUDSON, A., KIM, J., LAUGHON, A. and CARROLL, S. (1998). The Vestigial and Scalloped proteins act together to directly regulate wing-specific gene expression in Drosophila. Genes Dev 12: 3900-9.

HAWLEY, S.H., WUNNENBERG-STAPLETON, K., HASHIMOTO, C., LAURENT, M.N., WATABE, T., BLUMBERG, B.W. and CHO, K.W. (1995). Disruption of BMP signals in embryonic Xenopus ectoderm leads to direct neural induction Genes Dev 9: 2923-2935.

JIN, H.S., PARK, H.S., SHIN, J.H., KIM, D.H., JUN, S.H., LEE, C.J. and LEE, T.H. (2011). Anovel inhibitor of apoptosis protein (IAP)-interacting protein, Vestigial-like (Vgl)-4, counteracts apoptosis-inhibitory function of IAPs by nuclear sequestration. Biochem. Biophys. Res. Commun. 412: 454-459.

JOHNSON, C.W., HERNANDEZ-LAGUNAS, L., FENG, W., MELVIN, V.S., WILLIAMS T. and ARTINGER, K.B. (2011). Vgll2a is required for neural crest cell survival during zebrafish craniofacial development. Dev. Biol. 357: 269-281.

KIM, J., SEBRING, A., ESCH, J.J., KRAUS, M.E., VORWERK, K., MAGEE, J. and CARROLL, S.B. (1996). Integration of positional signals and regulation of wing formation and identity by Drosophila vestigial gene. Nature 382: 133-138.

KLEIN, S.L., STRAUSBERG, R.L., WAGNER, L., PONTIUS, J., CLIFTON, S.W. and RICHARDSON, P. (2002). Genetic and genomic tools for Xenopus research: The NIH Xenopus initiative. Dev. Dynamics 225: 384-391.

KOONTZ, L.M., LIU-CHITTENDEN, Y., YIN, F., ZHENG, Y., YU, J., HUANG, B., CHEN, Q., WU, S. and PAN, D. (2013). The Hippo effector Yorkie controls normal tissue growth by antagonizing scalloped-mediated default repression. Dev. Cell 25: 388-401.

MAEDA, T., CHAPMAN, D.L. and STEWART, A.F. (2002). Mammalian vestigial-like 2, a cofactor of TEF-1 and MEF2 transcription factors that promotes skeletal muscle differentiation. J. Biol. Chem. 277: 48889-48898.

MANN, C.J., OSBORN, D.P. and HUGHES, S.M. (2007). Vestigial-like-2b (VITO-1b) and Tead-3a (Tef-5a) expression in zebrafish skeletal muscle, brain and notochord. Gene Exp. Patt. 7: 827-836.

MELVIN, V.S., FENG, W., HERNANDEZ-LAGUNAS, L., ARTINGER, K.B. and WILLIAMS, T. (2013). A morpholino-based screen to identify novel genes involved in craniofacial morphogenesis. Dev. Dynamics 242: 817-831.

MONTERO-BALAGUER, M., LANG, M.R., SACHDEV, S.W., KNAPPMEYER, C., STEWART, R.A., DE LA GUARDIA, A., HATZOPOULOS, A.K. and KNAPIK, E.W. (2006). The mother superior mutation ablates foxd3 activity in neural crest progenitor cells and depletes neural crest derivatives in zebrafish. Dev. Dynamics 235: 3199-212.

POLLET, N., MUNCKE, N., VERBEeK, B., LI, Y., FENGER, U., DELIUS, H. and NIEHRS, C. (2005). An atlas of differential gene expression during early Xenopus embryogenesis. Mech. Dev. 122: 365-439.

RABADAN, M.A., USIETO, S., LAVARINO, C. and MARTI, E. (2013). Identification of a putative transcriptome signature common to neuroblastoma and neural crest cells. Dev. Neurobiol. 73: 815-827.

SIMMONDS, A.J., LIU, X., SOANES, K.H., KRAUSE, H.M., IRVINE, K.D. and BELL, J.B. (1998). Molecular interactions between Vestigial and Scalloped promote wing formation in Drosophila. Genes Dev. 12: 3815-3820.

TAJONAR, A., MAEHR, R., HU, G., SNEDDON, J.B., RIVERA-FELICIANO, J., COHEN, 
D.E., ELLEDGE, S.J. and MELTON, D.A. (2013). VGLL4 is a Novel Regulator of Survival in Human Embryonic Stem Cells. Stem Cells.

TAKAHASHI, N., TOCHIMOTO, N., OHMORI, S.Y., MAMADA, H., ITOH, M., INAMORI, M., SHINGA, J., OSADA, S. and TAIRA, M. (2005). Systematic screening for genes specifically expressed in the anterior neuroectoderm during early Xenopus development. Int. J. Dev. Biol. 49: 939-951.

THISSE, B., PFLUMIO, S., FÜRTHAUER, M., LOPPIN, B., HEYER, V., DEGRAVE, A., WOEHL, R., LUX, A., STEFFAN, T., CHARBONNIER, X.Q. THISSE, C. (2001) Expression of the zebrafish genome during embryogenesis (NIH R01 RR15402). ZFIN Direct Data Submission (http:///fin.org).

TRIBULO, C., AYBAR, M.J., SANCHEZ, S.S. and MAYOR, R. (2004). A balance between the anti-apoptotic activity of Slug and the apoptotic activity of msx1 is required for the proper development of the neural crest. Dev. Biol. 275: 325-42.
TRIBULO, C., GUADALUPE BARRIONUEVO, M., AGUERO, T.H., SANCHEZ, S.S., CALCATERRA, N.B. and AYBAR, M.J. (2012). DeltaNp63 is regulated by BMP4 signaling and is required for early epidermal development in Xenopus. Dev. Dynam. 241: 257-269.

VAUDIN, P., DELANOUE, R., DAVIDSON, I., SILBER, J. and ZIDER, A. (1999). TONDU (TDU), a novel human protein related to the product of vestigial $(\mathrm{vg})$ gene of Drosophila melanogaster interacts with vertebrate TEF factors and substitutes for Vg function in wing formation. Development 126: 4807-4816.

WILSON, P.A. and HEMMATI-BRIVANLOU, A. (1995). Induction of epidermis and inhibition of neural fate by Bmp-4. Nature 376: 331-333. 


\section{Further Related Reading, published previously in the Int. J. Dev. Biol.}

Vestigial like gene family expression in Xenopus: common and divergent features with other vertebrates Corinne Faucheux, François Naye, Karine Tréguer, Sandrine Fédou, Pierre Thiébaud and Nadine Thézé Int. J. Dev. Biol. (2010) 54: 1375-1382

http://dx.doi.org/10.1387/ijdb.103080cf

Differential expression of two TEF-1 (TEAD) genes during Xenopus laevis development and in response to inducing factors François Naye, Karine Tréguer, Fabienne Soulet, Corinne Faucheux, Sandrine Fédou, Nadine Thézé and Pierre Thiéboud

Int. J. Dev. Biol. (2007) 51: 745-752

http://www.ijdb.ehu.es/web/paper/072375fn

Msx1 and Msx2 have shared essential functions in neural crest but may be dispensable in epidermis and axis formation in Xenopus

Deepak Khadka, Ting Luo and Thomas D. Sargent

Int. J. Dev. Biol. (2006) 50: 499-502

http://dx.doi.org/10.1387/ijdb.052115dk

\section{BMP signalling in craniofacial development}

Xuguang Nie, keijo Luukko and Paivi Kettunen

Int. J. Dev. Biol. (2006) 50: 511-521

http://dx.doi.org/10.1387/ijdb.052101xn

Differential regulation of DIx gene expression bya a BMP morphogenetic gradient Ting Luo, Mami Matsuo-Takasaki, Jae H Lim and Thomas D Sargent

Int. J. Dev. Biol. (2001) 45: 681-684

http://dx.doi.org/10.1387/ijdb.11461005

5 yr ISI Impact Factor $(2011)=2.959$
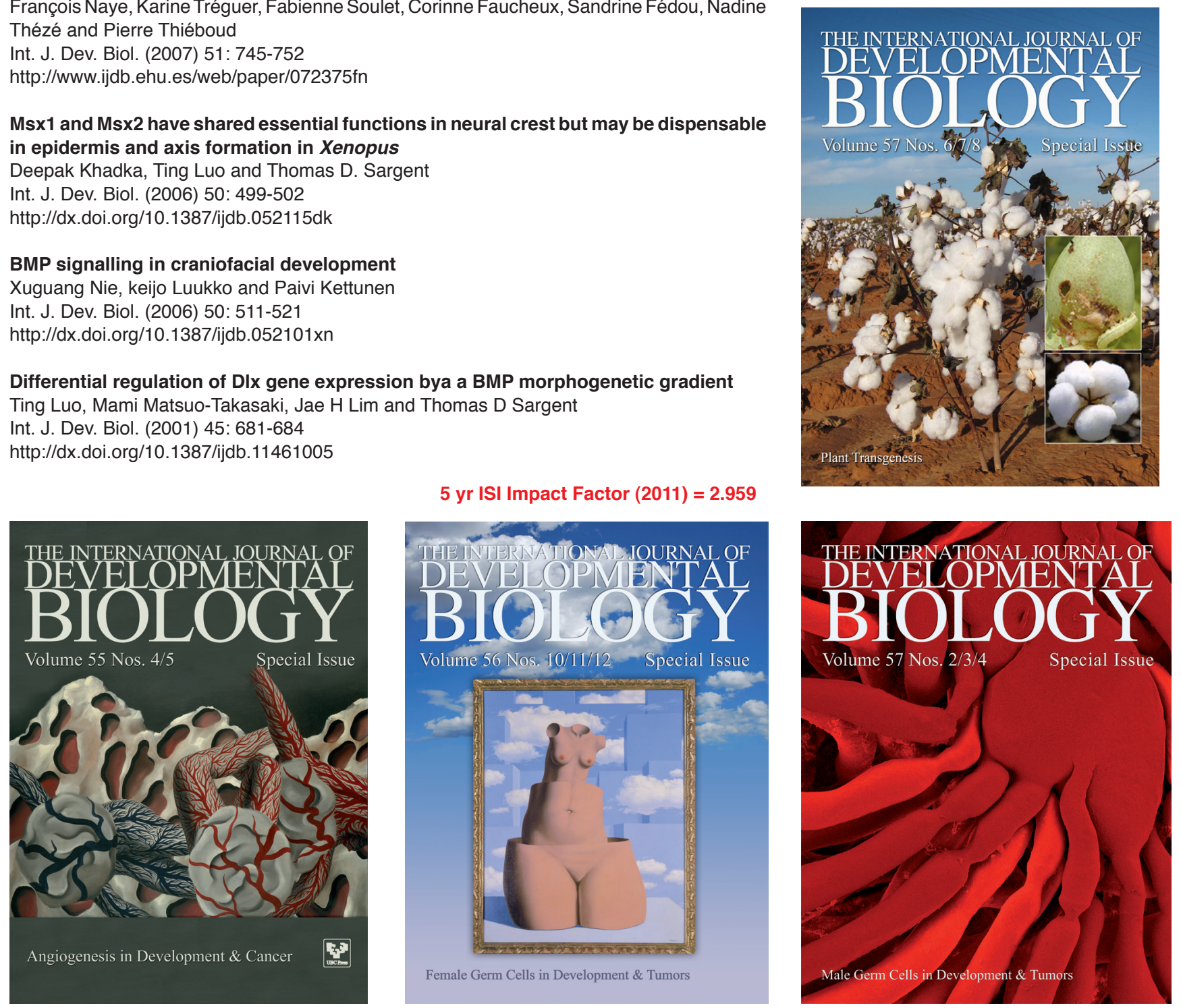